\title{
Low tumour-infiltrating Iymphocyte density in primary and recurrent glioblastoma
}

\author{
Kelsey Maddison ${ }^{1,4,5}$, Moira C. Graves ${ }^{2,4,5}$, Nikola A. Bowden ${ }^{2,4,5}$, Michael Fay ${ }^{2,4,5,6}$, \\ Ricardo E. Vilain ${ }^{2,3,5,7}$, Sam Faulkner ${ }^{1,5}$ and Paul A. Tooney ${ }^{1,4,5}$ \\ ${ }^{1}$ School of Biomedical Sciences and Pharmacy, The University of Newcastle, Callaghan, NSW, Australia \\ ${ }^{2}$ School of Medicine and Public Health, The University of Newcastle, Callaghan, NSW, Australia \\ ${ }^{3}$ Hunter Cancer Biobank, The University of Newcastle, Callaghan, NSW, Australia \\ ${ }^{4}$ Centre for Drug Repurposing and Medicines Research, The University of Newcastle, Callaghan, NSW, Australia \\ ${ }^{5}$ Hunter Medical Research Institute, New Lambton Heights, NSW, Australia \\ ${ }^{6}$ GenesisCare, Lake Macquarie Private Hospital, Gateshead, NSW, Australia \\ ${ }^{7}$ Pathology North, Hunter New England Area Health Service, New Lambton Heights, NSW, Australia \\ Correspondence to: Paul A. Tooney, email: Paul.Tooney@newcastle.edu.au
}

Keywords: glioblastoma; tumour-infiltrating lymphocytes; programmed cell death 1; tumour recurrence; immune microenvironment Abbreviations: CNS: Central nervous system; DAB: 3',3'-diaminobenzidine; PD-1: programmed cell death-1; PD-L1: programmed cell death ligand 1; TILs: tumour-infiltrating lymphocytes

Received: July 01,2021 Accepted: August 28, $2021 \quad$ Published: October 12, 2021

Copyright: () 2021 Maddison et al. This is an open access article distributed under the terms of the Creative Commons Attribution License (CC BY 3.0), which permits unrestricted use, distribution, and reproduction in any medium, provided the original author and source are credited.

\section{ABSTRACT}

Immunotherapies targeting tumour-infiltrating lymphocytes (TILs) that express the immune checkpoint molecule programmed cell death-1 (PD-1) have shown promise in preclinical glioblastoma models but have had limited success in clinical trials. To assess when glioblastoma is most likely to benefit from immune checkpoint inhibitors we determined the density of TILs in primary and recurrent glioblastoma. Thirteen cases of matched primary and recurrent glioblastoma tissue were immunohistochemically labelled for CD3, CD8, CD4 and PD-1, and TIL density assessed. CD3+ TILs were observed in all cases, with the majority of both primary $(69.2 \%)$ and recurrent $(61.5 \%)$ tumours having low density of TILs present. CD8+ TILs were observed at higher densities than CD4+ TILs in both tumour groups. PD-1+ TILs were sparse and present in only $\mathbf{2 5 \%}$ of primary and $50 \%$ of recurrent tumours. Quantitative analysis of TILs demonstrated significantly higher CD8+ TIL density at recurrence $(p=0.040)$. No difference was observed in CD3+ $(p=0.191)$, CD4+ $(p$ $=0.607)$ and PD-1+ $(p=0.070)$ TIL density between primary and recurrent groups. This study shows that TILs are present at low densities in both primary and recurrent glioblastoma. Furthermore, PD-1+ TILs were frequently absent, which may provide evidence as to why anti-PD-1 immunotherapy trials have been largely unsuccessful in glioblastoma.

\section{INTRODUCTION}

Glioblastoma, the most common and aggressive brain tumour occurring in adults, accounts for $\sim 56 \%$ of newly diagnosed central nervous system (CNS) cancers in Australia [1]. Standard treatment involves maximal safe surgical resection, followed by radiation therapy with concomitant and adjuvant temozolomide chemotherapy. In most cases, a treatment resistant recurrent tumour occurs, and median survival time remains short at 14.6 months [2].

Tumour-infiltrating lymphocytes (TILs) have been reported in a number of cancers. The immune checkpoint molecule, programmed cell death 1 (PD-1), is expressed by activated $\mathrm{T}$ cells and regulates immune responses by binding its ligand, programmed cell death ligand 1 (PDL1) [3], which can be expressed by tumour cells [4-9] 
Sustained antigen presentation and the binding of PD-L1 by TILs expressing PD-1 can result in T cell exhaustion and tumour evasion of immune responses [3, 10]. Immune checkpoint inhibition with anti-PD-1 antibodies blocks PD-1/PD-L1 interactions, restoring effector T cell proliferation and function [11]. This approach has been successful in some cancers including melanoma, where increased progression-free and overall survival, and higher response rates than treatment with chemotherapy have been observed [12]. In melanoma, response to anti-PD-1 immunotherapy has been associated with higher density of CD8+ (and PD-1+) TILs [11].

Until recently, the brain was considered an "immune privileged" site. However, peripheral antigen presenting cells and T cells have been reported in various locations in the CNS [13-15]. Dendritic cells have been identified among the antigen presenting cells that migrate to cervical lymph nodes, and are believed to contribute to CNS immunity and tolerance through antigen presentation to $\mathrm{T}$ cells at this site [15]. Under normal conditions, T cells are able to migrate to perivascular spaces within the brain and, in various disease states, antigen-specific T cells undergo a second stage of migration across the astrocytic endfeet barrier into the brain parenchyma [16].

TILs have been observed in glioblastoma, though findings in relation to their prognostic value have been inconsistent $[6,17-20]$. While a number of studies report the presence of TILs and/or detection of PD-1 and PD-L1 in immunohistochemical investigations of tumour tissue [6-9], these focus largely on primary glioblastoma, with very few comparisons to matched recurrent tumour tissue. As PD-1 presents a potential target for immunotherapy in glioblastoma, further research is warranted in order to clarify these inconsistencies.

Previous clinical trials conducted using anti-PD-1 immunotherapy in glioblastoma have demonstrated limited success [21, 22]. For example, the recent CheckMate 143 trial found no significant overall survival benefit in recurrent glioblastoma with anti-PD-1 when compared to the anti-angiogenic drug bevacizumab [23]. Another study reported similar anti-tumour activity when anti-PD-1 plus bevacizumab was compared to bevacizumab alone [24]. However, a recent study by Cloughesy et al (2019) [25] found that anti-PD-1 therapy given before and after recurrent tumour resection was associated with significant increases in overall survival compared to anti-PD-1 therapy given only after recurrent surgery. In contrast to prior studies assessing TILs in primary tumour tissue, the majority of clinical studies have assessed response to immunotherapy in recurrent glioblastoma. Given these discrepencies, and the finding by Cloughesy et al (2019) [25] of increased overall survival for patients treated with neoadjuvant anti-PD-1 at recurrence, we aimed to determine whether CD3+ TILs overall, or CD4+, CD8+ or PD-1+ TIL subsets, differed between matched samples of primary and recurrent glioblastoma and assess when anti-PD1 immunotherapy would be of most benefit.

\section{RESULTS}

\section{Categorical scoring}

Assessment of full-face tumour sections allowed for the observation of $\mathrm{T}$ cell presence and density across various topographies within each tumour (Figure 1). The overall level of TILs in glioblastoma tumours was very low. Only one tumour demonstrated marked CD3+ TIL density (a score of 3 ) relative to other glioblastomas (Figure 2 and Table 1), whilst the majority of both primary and recurrent tumours scored a 1, suggesting $\mathrm{T}$ cell infiltration into the tumour proper was low but not completely absent (Figure 2 and Table 1). CD8+ TILs were the dominant $\mathrm{T}$ cell subset present in the tumour tissue, demonstrating similar density to CD3+ TILs overall within the tumour proper. CD4+ TILs were observed less frequently and PD-1+ TILs were often completely absent (Table 1).

Similar to the tumour proper, perivascular CD3 $+\mathrm{T}$ cell density was predominantly low and similar between primary and recurrence (Table 1). The density of CD8+ $\mathrm{T}$ cells in perivascular spaces was higher at recurrence with $84.6 \%$ of cases having a score $\geq 1$, compared to $61.5 \%$ of primary tumours (Table 1 ). CD4+ T cells were predominantly scored $\leq 1$ in perivascular spaces in both primary (76.9\%) and recurrent $(92.3 \%)$ tumours. Again, PD-1+ T cells were virtually absent in the perivascular spaces of the majority of tumours (Table 1).

Signs of bleeding or previous haemorrhage included red blood cells within the tumour tissue or haemosiderin deposits. T cells in close proximity to these features were not considered to have infiltrated the tumour. Interestingly, in tumours with prominent haemosiderin deposits, these were associated with marked density of CD3 + T cells, and $\mathrm{T}$ cells in this location accounted for the majority of $\mathrm{T}$ cells observed in these cases (Figure 1 and Table 1). CD8+ $\mathrm{T}$ cells associated with bleeds followed a similar pattern, while CD4+ T cells were present at lower densities. PD$1+\mathrm{T}$ cells were not present in this topographical location in any primary tumours and present in only $16.7 \%$ of recurrent tumours in this location (Table 1).

\section{Quantitative scoring}

There were significant correlations between categorical and quantitative scoring methods for all $\mathrm{T}$ cell markers (Supplementary Table 1). There was no significant difference $(p=0.191)$ in CD3 + cell counts in the primary $\left(n=13\right.$, mean $139.88 \pm 108.60$ cells $\left./ \mathrm{mm}^{2}\right)$ compared to recurrent tumours $\left(n=13,226.30 \pm 156.55 \mathrm{cells} / \mathrm{mm}^{2}\right)$ (Figure 3A). Within T cell subsets, CD8+ TIL counts increased significantly $(p=0.040)$ in the recurrent tumours 
$\left(n=13,157.48 \pm 91.13\right.$ cells $\left./ \mathrm{mm}^{2}\right)$ compared to the primary tumours $\left(n=13,86.10 \pm 57.29\right.$ cells $\left./ \mathrm{mm}^{2}\right)$ (Figure 3B) with 9 of 13 cases showing higher CD8+ TILs at recurrence (Supplementary Figure 1). However, the CD4+ cell counts did not differ $(p=0.607)$ between primary $(n=$ $13,37.77 \pm 38.90$ cells $\left./ \mathrm{mm}^{2}\right)$ and recurrent groups $(n=13$, $49.93 \pm 42.33$ cells $/ \mathrm{mm}^{2}$ ) (Figure 3C). Whilst PD-1+ TIL density also increased slightly in recurrent $(n=11,24.21 \pm$ $21.69)$ compared to primary $(n=11,14 \pm 14.33)$ tumours, this trend was not significant ( $p=0.070)$ (Figure 3D).
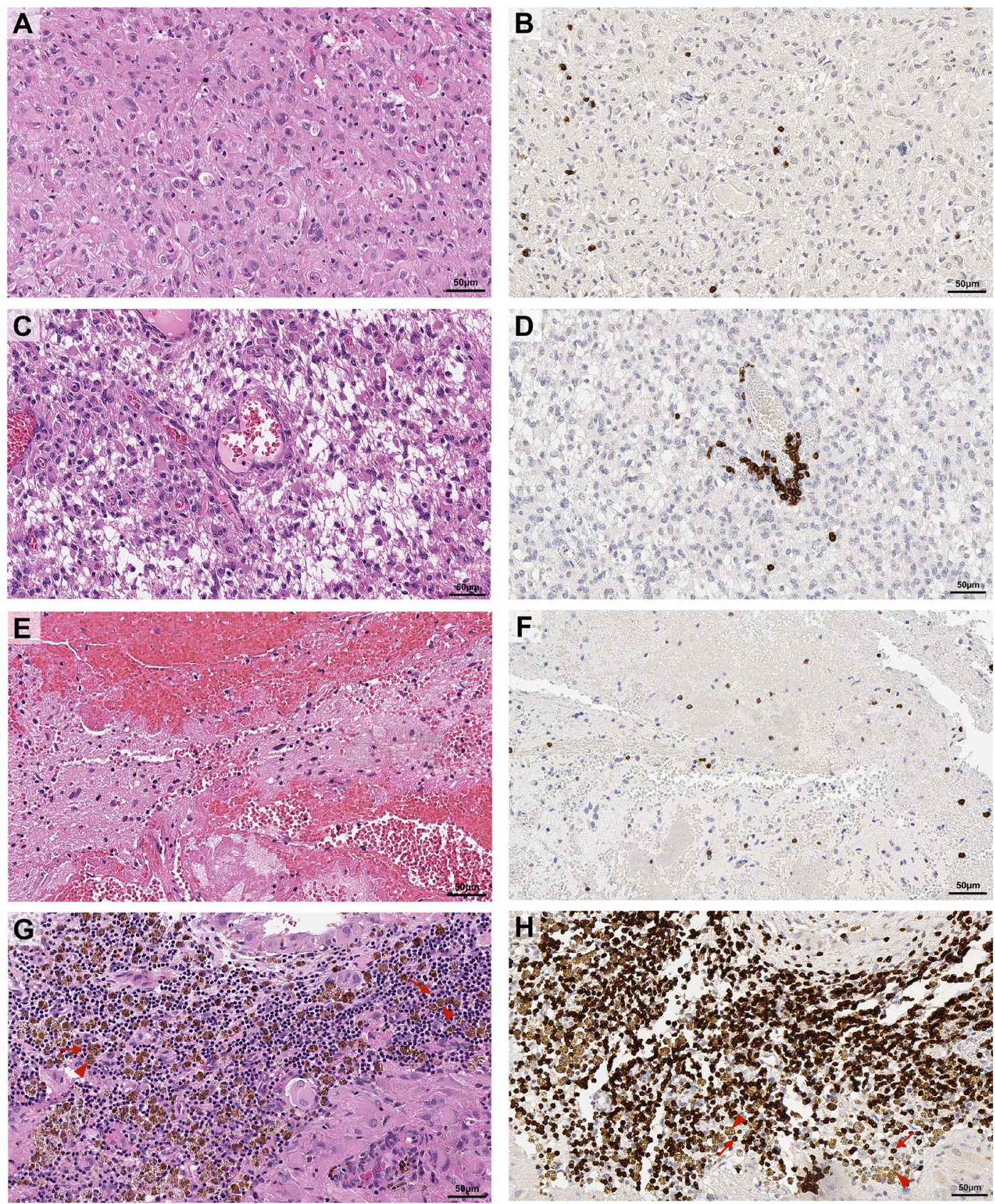

Figure 1: Representative images of topographical localisation of $\mathbf{T}$ cells in glioblastoma tumours. Glioblastoma sections were stained with H\&E (A, C, E, G) or labelled for CD3+ TILs by DAB immunohistochemistry $(\mathbf{B}, \mathbf{D}, \mathbf{F}, \mathbf{H})$. CD3+ TILs were located in the tumour proper $(\mathrm{A}, \mathrm{B})$, in perivascular spaces $(\mathrm{C}, \mathrm{D})$, associated with bleeds with prominent erythrocytes $(\mathrm{E}, \mathrm{F})$ and associated with haemosiderin deposits $(\mathrm{G}, \mathrm{H})$. Red arrows indicate TILs, red arrow heads indicate bronze haemosiderin deposits $(\mathrm{G}, \mathrm{H}) . \mathrm{Scale}$ bar $=50 \mu \mathrm{m}$. 
Table 1: Categorical density scores for CD3+, CD8+, CD4+, and PD-1+ TILs

\begin{tabular}{|c|c|c|c|c|c|c|c|c|}
\hline & \multicolumn{4}{|c|}{ Primary } & \multicolumn{4}{|c|}{ Recurrence } \\
\hline & $\mathbf{0}$ & 1 & 2 & 3 & $\mathbf{0}$ & 1 & 2 & 3 \\
\hline \multicolumn{9}{|l|}{ CD3 } \\
\hline Tumor & - & $9(69.2 \%)$ & $4(30.8 \%)$ & - & - & $8(61.5 \%)$ & $4(30.8 \%)$ & $1(7.7 \%)$ \\
\hline Perivascular & $2(15.4 \%)$ & $8(61.5 \%)$ & $2(15.4 \%)$ & $1(7.7 \%)$ & $2(15.4 \%)$ & $7(53.8 \%)$ & $4(30.8 \%)$ & - \\
\hline Bleeds & $7(53.8 \%)$ & $5(38.5 \%)$ & - & $1(7.7 \%)$ & $6(46.2 \%)$ & $4(30.8 \%)$ & - & $3(23.1 \%)$ \\
\hline \multicolumn{9}{|l|}{ CD8 } \\
\hline Tumor & - & $9(69.2 \%)$ & $4(30.8 \%)$ & - & - & $8(61.5 \%)$ & $4(30.8 \%)$ & $1(7.7 \%)$ \\
\hline Perivascular & $5(38.5 \%)$ & $6(46.2 \%)$ & $2(15.4 \%)$ & - & $2(15.4 \%)$ & $8(61.5 \%)$ & $3(23.1 \%)$ & - \\
\hline Bleeds & $8(61.5 \%)$ & $4(30.8 \%)$ & - & $1(7.7 \%)$ & $5(38.5 \%)$ & $5(38.5 \%)$ & $1(7.7 \%)$ & $2(15.4 \%)$ \\
\hline \multicolumn{9}{|l|}{ CD4 } \\
\hline Tumor & $9(69.2 \%)$ & $3(23.1 \%)$ & $1(7.7 \%)$ & - & $3(23.1 \%)$ & $9(69.2 \%)$ & $1(7.7 \%)$ & - \\
\hline Perivascular & $5(38.5 \%)$ & $5(38.5 \%)$ & $2(15.4 \%)$ & $1(7.7 \%)$ & $3(23.1 \%)$ & $9(69.2 \%)$ & $1(7.7 \%)$ & - \\
\hline Bleeds & $9(69.2 \%)$ & $3(23.1 \%)$ & - & $1(7.7 \%)$ & $6(46.2 \%)$ & $6(46.2 \%)$ & $1(7.7 \%)$ & - \\
\hline \multicolumn{9}{|l|}{ PD-1 } \\
\hline Tumor & $9(75.0 \%)$ & $3(25.0 \%)$ & - & - & $6(50.0 \%)$ & $4(41.6 \%)$ & $1(8.3 \%)$ & - \\
\hline Perivascular & $10(83.3 \%)$ & $2(16.7 \%)$ & - & - & $9(75.0 \%)$ & $3(25.0 \%)$ & - & - \\
\hline Bleeds & $12(100.0 \%)$ & - & - & - & $\begin{array}{c}10 \\
(83.3 \%)\end{array}$ & $2(16.7 \%)$ & - & - \\
\hline
\end{tabular}

primary and recurrent tumours, and determined whether changes occurred in these populations over the course of the disease. Importantly we examined PD-1+ T cell density to inform future studies assessing the suitability of anti-PD-1 immunotherapies in treatment of glioblastoma.

Categorical scoring for the $\mathrm{T}$ cell markers CD3, CD8, CD4 and PD-1 indicated that the density of TILs across both primary and recurrent glioblastoma tumours was low. It has been suggested that immunosuppression reported in glioblastoma is due to treatments, including radiation and temozolomide [31-33]. Additionally, patients are often treated with dexamethasone, a corticosteroid used to relieve the symptoms associated with oedema caused by the tumour [33, 34] but its immunosuppressive effects may reduce anti-tumour immunity $[33,35,36]$. However, the majority of cases in this cohort were considered not affected by dexamethasone or temozolomide at the time of surgery as the last reported dose was given more than 28 days prior to surgery. While the time since last dexamethasone dose and the amount given may differ between patients, only three cases in our cohort were known to have received dexamethasone at any dose within 28 days of surgery. Low TIL density across the cohort was therefore considered to be unlikely due to dexamethasone or temozolomide treatment. A previous study by Berghoff et al (2015) [6] yielded similar results, as CD3 + $\mathrm{T}$ cells were reported in the majority $(66.7 \%)$ of primary tumour sections assessed, but were present most frequently at low density. This study also reported no correlation between dexamethasone treatment prior to surgery and density of CD3+ TILs [6]. Alternatively, the low density of TILs observed in glioblastoma may result from the sequestration of naïve $\mathrm{T}$ cells in the bone marrow, as suggested by Chongsathidkiet et al (2018) [37]. However, further assessment of peripheral $\mathrm{T}$ cell populations is required to determine the extent to which this may contribute to lack of TILs in glioblastoma.

Both the categorical and quantitative scoring suggested that TILs were predominantly cytotoxic CD8+ $\mathrm{T}$ cells, with CD4+ $\mathrm{T}$ cells present less frequently and at lower densities across the cohort. Quantification of TILs revealed a significant increase in CD8+ T cells in recurrent compared to primary tumours. Tumeh et al (2014) [11] reported that a higher baseline density of CD8+ TILs was associated with response to anti-PD-1 immunotherapy in melanoma. However, the density of CD8+ TILs in patients that responded to anti-PD1 immunotherapy ranged from $\sim 500-8000$ cells $/ \mathrm{mm}^{2}$ in that study [11]. In contrast, we observed a mean density of $157.48 \pm 91.13$ $\mathrm{CD} 8+$ cells $/ \mathrm{mm}^{2}$ in recurrent glioblastoma. Furthermore, whilst a recent study by Klemm et al (2020) [38] using flow cytometry of tumour tissue showed higher levels of lymphocytes in glioblastoma compared to normal tissue, this level was still significantly less than that observed from melanoma brain metastases. Therefore, despite being statistically significant, the increase in CD8+ TILs that we observed in recurrent glioblastoma may not be enough to induce a biologically or clinically significant response to immunotherapy. We also acknowledge that small sample size is a limitation of our study, and whether an increase in CD8+ TILs is observed in a larger cohort of matched patient samples is yet to be confirmed. 
One study by Cloughesy et al (2019) [25] noted a significant increase in overall survival in 16 patients given anti-PD-1 immunotherapy before and after surgery to remove a recurrent glioblastoma, compared to 16 patients with a recurrence that received anti-PD-1 immunotherapy only after surgery. Whilst this study did not find a significant difference in CD8+ TILs between the two patient groups, some but not all patients given antiPD-1 immunotherapy before and after recurrent surgery had higher $\mathrm{CD} 8+$ cells compared to those patients given adjuvent therapy alone. Whether the significant increase in CD8+ TILs at recurrence in our cohort provides support for the study by Cloughesy et al (2019) needs to be interpreted with caution given the small cohort sizes of both studies.

Previous studies suggesting immunotherapy directed at PD-1 as a suitable treatment option for glioblastoma are based on the presence of PD-L1 in tumour tissue $[6,7]$, and the success of anti-PD-1 in preclinical models $[26,39]$. However, in order to assess PD-1, a number of prior studies such as those by Dejaegher et al (2017) [40] and Mohme et al (2018) [41], have used flow cytometry and reported a significant increase in PD-1 expression in $\mathrm{T}$ cells derived from glioblastoma tissue compared to peripheral blood. While flow cytometry has the benefit of being able to assess multiple markers on the same cell population, and can assess a larger number of cells than examination of tissue sections, it is not possible to know whether the cells of interest had indeed infiltrated the tumour tissue proper or were instead present in blood vessels, perivascular spaces, or as the result of haemorrhages, which were prominent in a number of cases in our study. Immunohistochemical analysis is considered to be the gold standard for assessing tumour infiltrating immune cells, as it accounts for localization and density of subsets of cells [42]. In agreement with previous immunohistochemical assessment of PD-1 [6, 8], our data demonstrate low density of PD-1+ TILs in only a minority of glioblastoma cases. If the current cohort is representative of glioblastoma cases, it is perhaps not

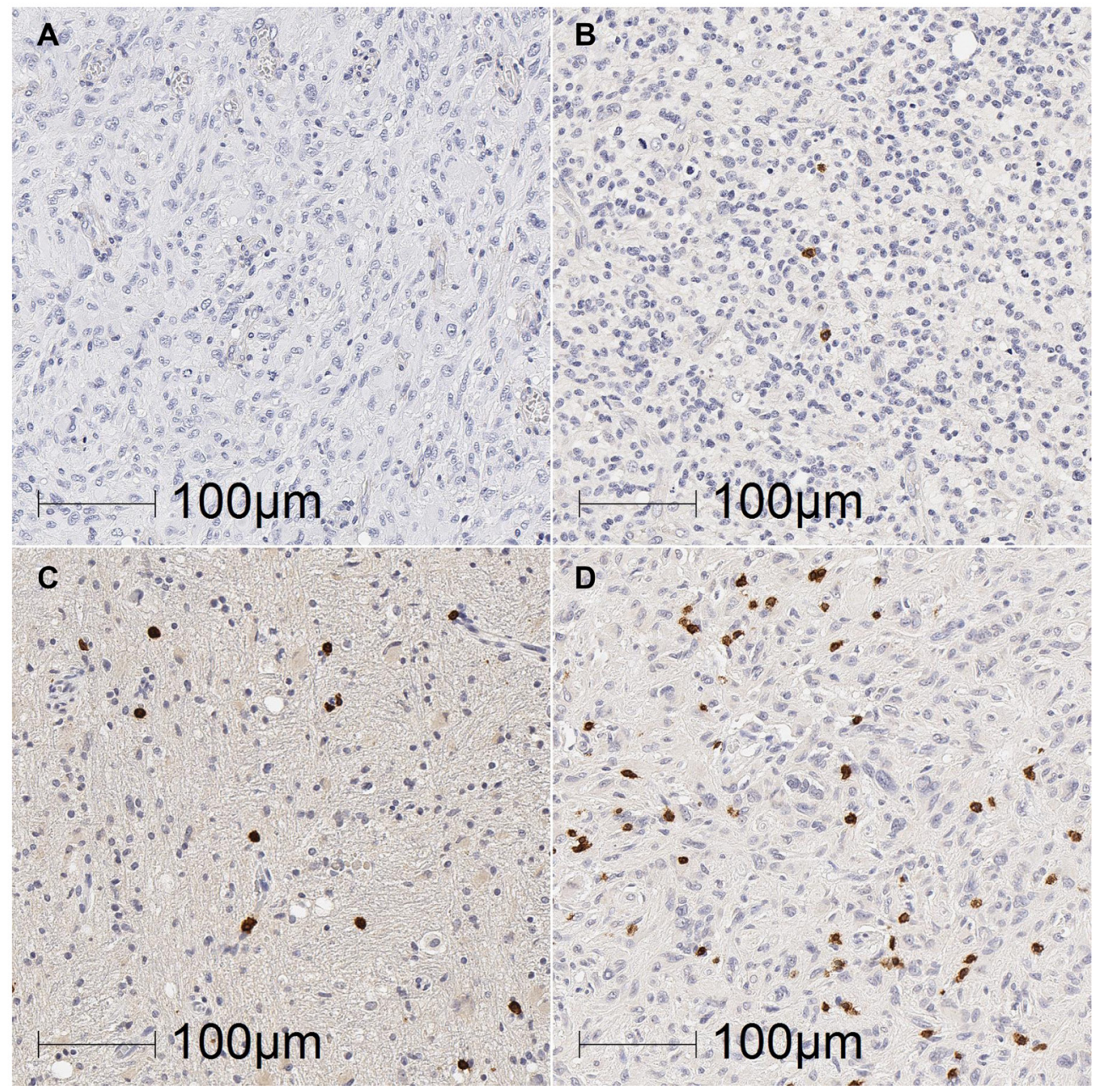

Figure 2: Representative images of TIL density in glioblastoma tumours. Glioblastoma sections were labelled for CD3+, CD8+, CD4+ and PD-1+ TILs by DAB immunohistochemistry and scored based on the density of TILs as 0 (absent; A), 1 (present; B), 2 (moderate; C), or 3 (marked; D). Representative images from sections labelled for CD3+ TILs (B, C and D) or CD4+ TILs (A; no sections labelled for CD3 had completely absent TILs). Scale bar $=100 \mu \mathrm{m}$. 
surprising that anti-PD-1 checkpoint inhibition approaches have not shown significant survival benefit for patients.

Large numbers of preclinical rodent models of glioblastoma have assessed the effects of antiPD-1 immune checkpoint inhibition alone [39] and in combination with various other treatments [26-28, 43], including radiation [26, 43] and temozolomide [43]. These studies have reported positive outcomes, including, but not limited to, long term-survival with single-agent anti-PD-1 [39], and survival enhanced by combination anti-PD-1 and radiation, which was attributed to increased cytotoxic CD8+ T cell infiltration [26]. Long term tumour-specific immune memory that prevented tumour development after tumour rechallenge has also been reported [26, 39]. While these studies use immunocompetent models of rodent glioma, suggesting they are relevant for assessing immune responses and immunotherapeutic approaches, rodent models have been reported to lack the diagnostically necessary histological characteristics that are seen in spontaneous human glioblastoma (i.e., palisading necrosis or microvascular proliferation) [44]. As rodent gliomas may not accurately represent human glioblastomas, response to anti-PD-1 treatment in these models may not be indicative of its clinical efficacy.

Glioblastomas are highly vascular with increased angiogenic activity associated with the presence of hemorrhaging [45] and increased presence of $\mathrm{T}$ cells [17]. Indeed, perivascular T cells were common in both primary and recurrent tumours in our cohort and $\mathrm{Mu}$ et al (2017) [46] found that the majority of T cells in both primary and recurrent glioblastoma were present in this location. However, perivascular $\mathrm{T}$ cells have also been reported in brain tissue without history of neurological or neuroinflammatory conditions [14], and in cohorts with neurological and neurodegenerative conditions [47]. Whether perivascular $\mathrm{T}$ cell density differs in glioblastoma and is associated with patient outcomes warrants investigation. We also observed CD3 $+\mathrm{T}$ cells in bleeds and associated with haemosiderin deposits, which indicate the occurrence of a previous haemorrhage. In cases with very prominent haemosiderin this accounted for the majority of T cells present in the tumour. It is therefore possible that $\mathrm{T}$ cells observed in association with bleeds have entered the tissue as a result of haemorrhage, as opposed to infiltrating the tumour as part of an immune response. This should be taken into consideration when designing studies using tumour tissue that has undergone dissolution to provide single cell suspensions for flow cytometric analysis of immune cell populations.

A limitation of our study is that it did not assess the relationship between TIL density and presence of tumour-associated macrophages. Tumour-associated macrophages including peripheral macrophages and resident microglia, are the major infiltrating immune cell population in primary $[6,48]$ and recurrent glioblastoma [49]. Tumour-associated macrophages are able to adopt tumour supportive, immunosuppressive phenotypes in response to stimuli from the surrounding environment, and therefore may impact TIL populations. For example, tumour-associated macrophages from glioblastoma have been reported to lack the costimulatory molecules CD86, CD80 and CD40, suggesting that they are not able to effectively support activation of $\mathrm{T}$ cells [48]. Future studies should incorporate assessment of macrophage/ microglia populations in tissue from primary and recurrent glioblastoma.

Variability of PD-L1 labelling within and between tissue sections in this cohort also presented a limitation. The criteria relating to $\mathrm{PD}-\mathrm{L} 1$ expression that determine suitability of treatment with anti-PD-1/anti-PD-L1 immunotherapies vary between tumours. For example, checkpoint inhibition is considered as a first line therapy in non-small cell lung cancer if greater than $50 \%$ of tumour cells demonstrate membranous PD-L1 labelling [50], while for urothelial carcinoma both the presence of immune cells in the tumour and the percentage of immune
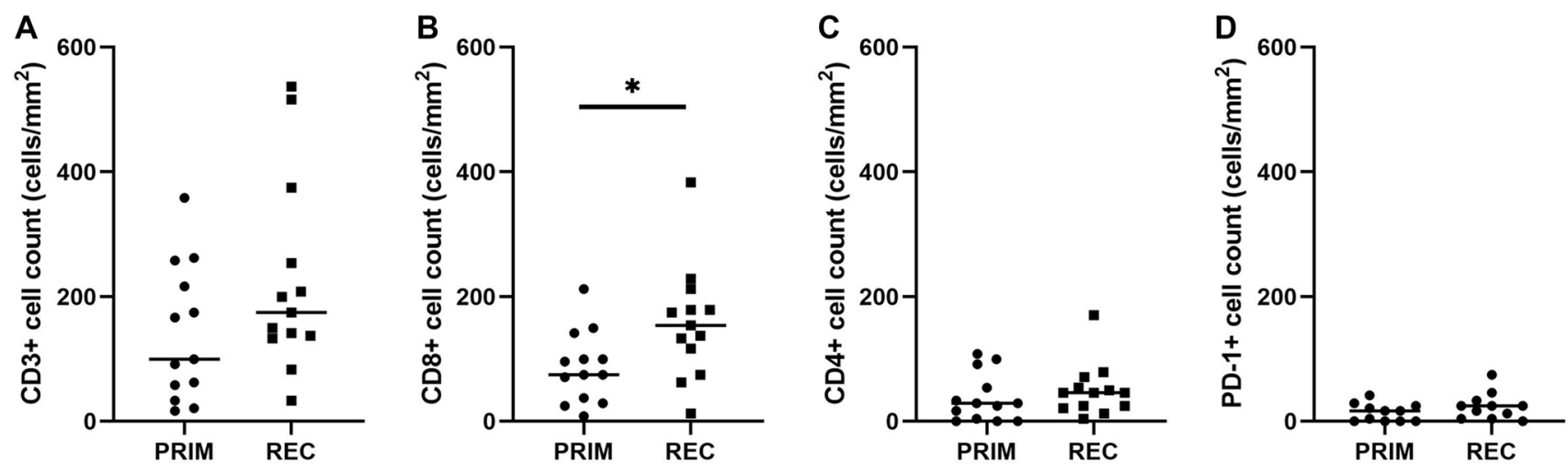

Figure 3: Quantitative TIL scores in primary and recurrent glioblastoma. Density of CD3+, CD8+, CD4+ and PD-1+ TILs was calculated for each case and compared between primary and recurrent groups. No difference was seen in overall CD3+ TIL density $(p=0.191 ; \mathbf{A})$ CD8+ TILs were present at significantly higher density in recurrent tumours compared to primary tumours $(p=0.040 ; \mathbf{B})$. No differences were seen in CD4+ TIL density $(p=0.607 ; \mathbf{C})$ or PD-1+ TIL density $(p=0.070$; D). Bars represent median score. PRIM: primary tumour, REC: recurrent tumour. 
cells with positive PD-L1 labelling inform the decision to treat with immunotherapy [51]. Given that PD-L1 labelling occurred in multiple cell types and cellular localisations within and between tumours in our cohort (data not shown), determining the significance of each labelling pattern was not possible in a cohort of this size.

In summary, the level of T cell infiltration seen in this small cohort of matched primary and recurrent glioblastoma tissue was low. Though the number of CD8+ TILs was significantly higher in recurrent compared to primary tumours, overall TIL density at recurrence was still mild. PD-1+ TILs in particular were absent in the majority of our cases. Whether this is why many clinical trials using antiPD-1 immunotherapy have not shown significant survival benefit in glioblastoma requires further investigation.

\section{MATERIALS AND METHODS}

\section{Patient cohort}

This study was approved by the Human Research Ethics Committee of the University of Newcastle (H2018-0007). Formalin-fixed paraffin-embedded tumour tissue from maximal safe surgical resection was sourced from the Hunter Cancer Biobank (HCB) for 13 cases of glioblastoma with matched primary and recurrent tissue (Table 2). A block containing maximal tumour content was chosen from each patient and diagnosis of glioblastoma confirmed on $\mathrm{H} \& \mathrm{E}$ stained sections by a neuropathologist (REV). Clinical and demographic information available for the cohort included age, gender, location of primary tumour, $I D H 1$ mutation status, treatment information, and progression-free survival and overal survival information. MGMT promoter methylation status has also been reported where it was available in the clinical information. Ten of the 13 cases received standard treatment with radiation and temozolomide following the removal of the primary tumour. Complete treatment information was not available for two of the 13 cases (numbers 5 and 15), and one case (number 10) commenced radiation and temozolomide treatment following removal of the recurrent tumour (Table 2). Patients were considered as having had dexamethasone or temozolomide at the time of surgery if the last known date of drug treatment was within 28 days of the date of surgery. Only cases 9, 10 and 12 were known to have received dexamethasone and only case 9 was known to have received temozolomide within 28 days of recurrent surgery (Table 2). Additionally, the time between last dose of radiation and recurrent surgery was greater than 28 days for 10 of the 13 cases, unknown for two cases, and there was one case not treated with radiation prior to tumour recurrence.

\section{Immunohistochemistry}

Formalin-fixed paraffin-embedded tumour tissue was sliced into $4 \mu \mathrm{m}$ full face sections and processed for 3',3'-diaminobenzidine (DAB) immunohistochemistry using a Ventana Discovery Ultra (Roche, USA) by the HCB. Sections were labelled for T cell markers CD3 (2GV6; Roche), CD4 (SP35; Roche), CD8 (SP57; Roche), and PD-1 (NAT105; Sigma-Aldrich, USA). All steps from baking to chromogen addition were performed automatically by the instrument. Tissue sections were baked to slides and deparaffinized, and antigen retrieval then occurred at $95^{\circ} \mathrm{C} / \mathrm{pH} 9$ with a total incubation time of 24 minutes prior to the addition of the primary antibody. Addition of the primary antibody was followed by a 32 -minute incubation at $36^{\circ} \mathrm{C}$. For $\mathrm{CD} 4$ labelling only, the primary antibody was dispensed before the blocking step, resulting in a reduction of non-specific labelling in the tumour tissue. Slides were then incubated with secondary antibody - Anti-Rabbit HQ for CD3, CD4 and CD8, and Anti-Mouse HQ (Roche) for PD-1 - for 20 minutes at $36^{\circ} \mathrm{C}$. Positive control (normal tonsil) and negative control (normal brain) tissues were included in each batch of slides to confirm the specificity of antibody labelling (Supplementary Figure 2). Slides were digitally scanned using the Aperio ${ }^{\mathrm{TM}}$ Digital AT2 Pathology System (Leica Biosystems, Australia) for analysis.

\section{Categorical TIL scoring}

The scoring system used for CD3, CD4, CD8 and PD-1 labelled tissue was developed in consultation with an experienced neuropathologist (REV) and based on the association of positive cells with characteristic topographical features of glioblastoma: tumour proper, perivascular areas (i.e., closely associated with blood vessels), and bleeds/haemorrhages (Figure 1). Signs of haemorrhage included presence of red blood cells or haemosiderin deposits within the tumour tissue (Figure 1). Digitised slides were assessed by scanning across the whole tissue section at $40 \times$ absolute magnification, with higher magnifications of $100-200 \times$ used as necessary to confirm $\mathrm{T}$ cell labelling or topographical features of the tissue. $\mathrm{CD} 3+, \mathrm{CD} 4+, \mathrm{CD} 8+$, and $\mathrm{PD}-1+$ cells in each topographical area were given a density score of 0 - absent, 1 - present, 2 - moderate, or 3 - marked (Figure 2). Scoring was performed independently by two investigators (KM and PAT), and discrepancies were discussed and adjusted to determine final scores for each tissue section.

\section{Quantitative TIL scoring}

HALO image analysis software (version 1; Indica Labs, USA) was used to quantify CD3+ and CD8+ TILs in the tumour proper of tissue sections labelled by immunohistochemistry. Based on CD3+ labelling, the software was trained to recognise DAB labelled T cells as positive, and to count these cells using a modified version of the inbuilt CytoNuclear analysis algorithm. Analysis 
Table 2: Demographic and clinical information available for glioblastoma cohort

\begin{tabular}{|c|c|c|c|c|c|c|c|c|c|c|c|}
\hline \multirow[t]{2}{*}{$\begin{array}{c}\text { Case } \\
\text { number }\end{array}$} & \multirow[t]{2}{*}{ Gender } & \multirow[t]{2}{*}{$\begin{array}{c}\text { Age at } \\
\text { diagnosis }\end{array}$} & \multirow[t]{2}{*}{$\begin{array}{l}\text { Primary tumour } \\
\text { location }\end{array}$} & \multirow[t]{2}{*}{$\begin{array}{l}\text { Treatment at } \\
\text { primary }\end{array}$} & \multirow{2}{*}{$\begin{array}{l}\text { IDH1 } \\
\text { mutation } \\
\text { status }\end{array}$} & \multirow{2}{*}{$\begin{array}{c}\text { MGMT } \\
\text { promoter } \\
\text { methylation }\end{array}$} & \multirow[t]{2}{*}{$\begin{array}{l}\text { PFS } \\
\text { (days) }\end{array}$} & \multirow[t]{2}{*}{$\begin{array}{c}\text { OS } \\
\text { (days) }\end{array}$} & \multicolumn{2}{|c|}{$\begin{array}{l}\text { Dexamethasone at surgery (days } \\
\text { prior to surgery, dose) }\end{array}$} & \multirow{2}{*}{$\begin{array}{c}\text { TMZ at recurrent } \\
\text { surgery (days prior to } \\
\text { surgery) }\end{array}$} \\
\hline & & & & & & & & & Primary & Recurrence & \\
\hline 2 & M & 39 & Frontal lobe & RT/TMZ & WT & No & 455 & $462^{\mathrm{a}}$ & No & No & No \\
\hline 3 & F & 77 & $\begin{array}{l}\text { Left inferolateral } \\
\text { temporal lobe }\end{array}$ & $\mathrm{RT} / \mathrm{TMZ}$ & WT & Unknown & 938 & 1036 & No & No & No \\
\hline 4 & $\mathrm{~F}$ & 45 & Left frontal lobe & $\mathrm{RT} / \mathrm{TMZ}$ & WT & Unknown & 398 & 679 & No & No & No \\
\hline 5 & M & 76 & Right frontal lobe & Unknown & WT & Unknown & 315 & $316^{\mathrm{a}}$ & Unknown & Unknown & Unknown \\
\hline 6 & M & 72 & $\begin{array}{l}\text { Right temporoparietal } \\
\text { lobe }\end{array}$ & $\mathrm{RT} / \mathrm{TMZ}$ & WT & Unknown & 266 & 343 & No & No & No \\
\hline 7 & M & 42 & Frontal lobe & RT/TMZ & WT & Unknown & 374 & 453 & No & No & No \\
\hline 8 & $\mathrm{~F}$ & 81 & Right temporal lobe & $\mathrm{RT} / \mathrm{TMZ}$ & WT & Unknown & 277 & 427 & Unknown & Unknown & No \\
\hline 9 & M & 40 & $\begin{array}{l}\text { Anterior left temporal } \\
\text { lobe }\end{array}$ & $\mathrm{RT} / \mathrm{TMZ}$ & WT & Unknown & 116 & 410 & No & Yes $\left(26\right.$ days $\left.^{b}\right)$ & Yes (13 days) \\
\hline 10 & M & 55 & Right frontal lobe & None & WT & No & 38 & $177^{\mathrm{a}}$ & No & $\begin{array}{l}\text { Yes ( } 9 \text { days, } \\
\quad 1 \mathrm{mg})\end{array}$ & No \\
\hline 11 & M & 72 & Left temporal lobe & RT/TMZ & WT & Unknown & 300 & 387 & No & No & No \\
\hline 12 & M & 45 & Left temporal lobe & $\mathrm{RT} / \mathrm{TMZ}$ & WT & No & 206 & 468 & Unknown & $\begin{array}{l}\text { Yes }(2 \text { days, } \\
2 \mathrm{mg})\end{array}$ & No \\
\hline 13 & F & 64 & $\begin{array}{l}\text { Right posterior } \\
\text { temporoparietal lobe }\end{array}$ & $\mathrm{RT} / \mathrm{TMZ}$ & WT & Unknown & 252 & 919 & No & No & No \\
\hline 15 & F & 65 & $\begin{array}{l}\text { Posterior right frontal } \\
\text { lobe }\end{array}$ & Unknown & WT & Yes & 310 & 353 & Unknown & No & Unknown \\
\hline
\end{tabular}

Abbreviations: RT: radiation therapy; TMZ: temozolomide; IDHI: isocitrate dehydrogenase 1; WT: wild-type; MGMT: O-6-methylguanine-DNA methyltransferase; PFS: progression-free survival; OS: overall survival. ${ }^{a}$ Lost to follow-up. ${ }^{b}$ Started at $2 \mathrm{mg}$ and weaned to $0 \mathrm{mg}$ at 26 days prior to surgery.

parameters were adjusted until HALO could recognise and quantify DAB labelled cells accurately across a number of regions representative of TIL infiltration within and between tissue sections.

Whole tissue sections labelled for CD3 were examined within the HALO software at $40 \times$ magnification and four areas of highest CD3+ cell density within the tumour proper were identified. An annotation region of 245 $\times 245 \mu \mathrm{m}\left(\sim 60,000 \mu \mathrm{m}^{2}\right)$ was placed in each of the four hotspot areas and the number of CD3+ cells within each annotation quantified by HALO. Annotation regions were placed at least $245 \mu \mathrm{m}$ from: other annotations, large blood vessels, necrotic tissue, haemorrhages, any "normal" tissue, and the edges of the tissue section. The mean density of TILs was determined based on positive cell counts within the four annotation regions for each tissue section. This process was repeated for CD8, CD4 and PD-1 labelled slides, placing annotations in the same hotspot regions as for the CD3 labelled sections. HALO was unable to accurately identify CD4+ and PD-1+ cells due to lower DAB intensity in CD4+ and PD-1+ cells and the presence of CD4 labelling in additional cell types. Positively labelled CD4+ and PD$1+$ cells were therefore identified based on morphology and counted manually in each $245 \times 245 \mu \mathrm{m}$ annotated region.

\section{Statistical analysis}

Two-tailed Wilcoxon matched pairs signed rank tests were used for all paired datasets to determine whether TIL density differed between primary and recurrent glioblastomas. Statistical analyses were performed using Prism software (version 8.1.2 GraphPad Software, USA) or SPSS (version 25, IBM Corporation, USA) and $p<0.05$ was considered significant.

\section{Author contributions}

Kelsey Maddison: contributed to project design, collected the data, completed the analyses and wrote the manuscript. Moira Graves: contributed to project design, provided expertise and knowledge of the immune markers for TILs and edited the manuscript. Nikola Bowden: contributed to project design, provided expertise in TIL counting methodology, data analysis and edited the manuscript. Michael Fay: contributed to project design, provided clinical input and expertise on interpretation of the clinical data and edited the manuscript. Ricardo Vilain: contributed to project design, provided expert neuropathology input into the identification of the glioblastoma tumour tissue, TIL identification/counting, interpretation of the immunohistochemistry labeling and edited the manuscript. Sam Faulkner: contributed to data collection and analysis using HALO and edited the manuscript. Paul Tooney: directed and designed the project, assisted with collecting TIL data and edited the manuscript.

\section{ACKNOWLEDGMENTS}

The authors acknowledge the staff of the Hunter Cancer Biobank, University of Newcastle (particularly 
Melissa Tooney and Cassandra Griffin for sourcing the glioblastoma tumour tissue and clinical information and Megan Clarke for completing the immunohistochemistry) and Fiona Richards and her staff from the Histology Facility at the Hunter Medical Research Institute for scanning all the slides.

\section{CONFLICTS OF INTEREST}

Authors have no conflicts of interest to declare.

\section{FUNDING}

This work was supported by a Faculty of Health and Medicine Strategic Pilot Grant, University of Newcastle, and the Mark Hughes Foundation Clinical Research Fellowship to Michael Fay.

\section{REFERENCES}

1. Australian Institute of Health and Welfare. Brain and other central nervous system cancers. Canberra: AIHW; 2017. https://www.aihw.gov.au/getmedia/d2914a17-052e-45bbbbd3-17047c7d5da1/20566.pdf.aspx?inline=true.

2. Stupp R, Mason WP, van den Bent MJ, Weller M, Fisher B, Taphoorn MJ, Belanger K, Brandes AA, Marosi C, Bogdahn U, Curschmann J, Janzer RC, Ludwin SK, et al, and European Organisation for Research and Treatment of Cancer Brain Tumor and Radiotherapy Groups, and National Cancer Institute of Canada Clinical Trials Group. Radiotherapy plus concomitant and adjuvant temozolomide for glioblastoma. N Engl J Med. 2005; 352:987-96. https:// doi.org/10.1056/NEJMoa043330. [PubMed]

3. Sharpe AH, Wherry EJ, Ahmed R, Freeman GJ. The function of programmed cell death 1 and its ligands in regulating autoimmunity and infection. Nat Immunol. 2007; 8:239-45. https://doi.org/10.1038/ni1443. [PubMed]

4. Taube JM, Anders RA, Young GD, Xu H, Sharma R, McMiller TL, Chen S, Klein AP, Pardoll DM, Topalian SL, Chen L. Colocalization of inflammatory response with B7-h1 expression in human melanocytic lesions supports an adaptive resistance mechanism of immune escape. Sci Transl Med. 2012; 4:127ra37. https://doi.org/10.1126/ scitranslmed.3003689. [PubMed]

5. Velcheti V, Schalper KA, Carvajal DE, Anagnostou VK, Syrigos KN, Sznol M, Herbst RS, Gettinger SN, Chen L, Rimm DL. Programmed death ligand-1 expression in nonsmall cell lung cancer. Lab Invest. 2014; 94:107-16. https:// doi.org/10.1038/labinvest.2013.130. [PubMed]

6. Berghoff AS, Kiesel B, Widhalm G, Rajky O, Ricken G, Wöhrer A, Dieckmann K, Filipits M, Brandstetter A, Weller M, Kurscheid S, Hegi ME, Zielinski CC, et al. Programmed death ligand 1 expression and tumor-infiltrating lymphocytes in glioblastoma. Neuro Oncol. 2015; 17:1064-75. https:// doi.org/10.1093/neuonc/nou307. [PubMed]
7. Nduom EK, Wei J, Yaghi NK, Huang N, Kong LY, Gabrusiewicz K, Ling X, Zhou S, Ivan C, Chen JQ, Burks JK, Fuller GN, Calin GA, et al. PD-L1 expression and prognostic impact in glioblastoma. Neuro Oncol. 2016; 18:195-205. https://doi.org/10.1093/neuonc/nov172. [PubMed]

8. Garber ST, Hashimoto Y, Weathers SP, Xiu J, Gatalica Z, Verhaak RG, Zhou S, Fuller GN, Khasraw M, de Groot J, Reddy SK, Spetzler D, Heimberger AB. Immune checkpoint blockade as a potential therapeutic target: surveying CNS malignancies. Neuro Oncol. 2016; 18:1357-66. https://doi. org/10.1093/neuonc/now132. [PubMed]

9. Han J, Hong Y, Lee YS. PD-L1 Expression and Combined Status of PD-L1/PD-1-Positive Tumor Infiltrating Mononuclear Cell Density Predict Prognosis in Glioblastoma Patients. J Pathol Transl Med. 2017; 51:4048. https://doi.org/10.4132/jptm.2016.08.31. [PubMed]

10. Ahmadzadeh M, Johnson LA, Heemskerk B, Wunderlich JR, Dudley ME, White DE, Rosenberg SA. Tumor antigen-specific CD8 $\mathrm{T}$ cells infiltrating the tumor express high levels of PD-1 and are functionally impaired. Blood. 2009; 114:1537-44. https://doi.org/10.1182/ blood-2008-12-195792. [PubMed]

11. Tumeh PC, Harview CL, Yearley JH, Shintaku IP, Taylor EJ, Robert L, Chmielowski B, Spasic M, Henry G, Ciobanu V, West AN, Carmona M, Kivork C, et al. PD-1 blockade induces responses by inhibiting adaptive immune resistance. Nature. 2014; 515:568-71. https://doi.org/10.1038/ nature13954. [PubMed]

12. Robert C, Long GV, Brady B, Dutriaux C, Maio M, Mortier L, Hassel JC, Rutkowski P, McNeil C, Kalinka-Warzocha E, Savage KJ, Hernberg MM, Lebbé C, et al. Nivolumab in previously untreated melanoma without BRAF mutation. N Engl J Med. 2015; 372:320-30. https://doi.org/10.1056/ NEJMoa1412082. [PubMed]

13. Pashenkov M, Huang YM, Kostulas V, Haglund M, Söderström M, Link H. Two subsets of dendritic cells are present in human cerebrospinal fluid. Brain. 2001; 124:48092. https://doi.org/10.1093/brain/124.3.480. [PubMed]

14. Kivisäkk P, Mahad DJ, Callahan MK, Trebst C, Tucky B, Wei T, Wu L, Baekkevold ES, Lassmann H, Staugaitis SM, Campbell JJ, Ransohoff RM. Human cerebrospinal fluid central memory CD4+ $\mathrm{T}$ cells: evidence for trafficking through choroid plexus and meninges via P-selectin. Proc Natl Acad Sci U S A. 2003; 100:8389-94. https://doi. org/10.1073/pnas. 1433000100. [PubMed]

15. Mohammad MG, Tsai VWW, Ruitenberg MJ, Hassanpour M, Li H, Hart PH, Breit SN, Sawchenko PE, Brown DA. Immune cell trafficking from the brain maintains CNS immune tolerance. J Clin Invest. 2014; 124:1228-41. https://doi.org/10.1172/JCI71544. [PubMed]

16. Mastorakos P, McGavern D. The anatomy and immunology of vasculature in the central nervous system. Sci Immunol. 2019; 4:eaav0492. https://doi.org/10.1126/sciimmunol. aav0492. [PubMed] 
17. Lohr J, Ratliff T, Huppertz A, Ge Y, Dictus C, Ahmadi R, Grau S, Hiraoka N, Eckstein V, Ecker RC, Korff T, von Deimling A, Unterberg A, et al. Effector T-cell infiltration positively impacts survival of glioblastoma patients and is impaired by tumor-derived TGF- $\beta$. Clin Cancer Res. 2011; 17:4296-308. https://doi.org/10.1158/1078-0432.CCR-102557. [PubMed]

18. Yang I, Tihan T, Han SJ, Wrensch MR, Wiencke J, Sughrue ME, Parsa AT. CD8+ T-cell infiltrate in newly diagnosed glioblastoma is associated with long-term survival. J Clin Neurosci. 2010; 17:1381-85. https://doi.org/10.1016/j. jocn.2010.03.031. [PubMed]

19. Han S, Zhang C, Li Q, Dong J, Liu Y, Huang Y, Jiang T, Wu A. Tumour-infiltrating CD4(+) and CD8(+) lymphocytes as predictors of clinical outcome in glioma. Br J Cancer. 2014; 110:2560-68. https://doi.org/10.1038/bjc.2014.162. [PubMed]

20. Safdari H, Hochberg FH, Richardson EP Jr. Prognostic value of round cell (lymphocyte) infiltration in malignant gliomas. Surg Neurol. 1985; 23:221-26. https://doi. org/10.1016/0090-3019(85)90086-2. [PubMed]

21. Lynes J, Sanchez V, Dominah G, Nwankwo A, Nduom E. Current Options and Future Directions in Immune Therapy for Glioblastoma. Front Oncol. 2018; 8:578. https://doi. org/10.3389/fonc.2018.00578. [PubMed]

22. Filley AC, Henriquez M, Dey M. Recurrent glioma clinical trial, CheckMate-143: the game is not over yet. Oncotarget. 2017; 8:91779-94. https://doi.org/10.18632/ oncotarget.21586. [PubMed]

23. Reardon DA, Brandes AA, Omuro A, Mulholland P, Lim M, Wick A, Baehring J, Ahluwalia MS, Roth P, Bähr O, Phuphanich S, Sepulveda JM, De Souza P, et al. Effect of Nivolumab vs Bevacizumab in Patients With Recurrent Glioblastoma: The CheckMate 143 Phase 3 Randomized Clinical Trial. JAMA Oncol. 2020; 6:1003-10. https://doi. org/10.1001/jamaoncol.2020.1024. [PubMed]

24. Reardon DA, Nayak L, Peters KB, Clarke JL, Jordan JT, de Groot JF, Nghiemphu PL, Kaley TJ, Colman H, Gaffey SC, Caruso V, Debruyne MB, Bhavsar C, et al. Phase II study of pembrolizumab or pembrolizumab plus bevacizumab for recurrent glioblastoma (rGBM) patients. J Clin Oncol. 2018; 36:2006. https://doi.org/10.1200/JCO.2018.36.15 suppl.2006.

25. Cloughesy TF, Mochizuki AY, Orpilla JR, Hugo W, Lee AH, Davidson TB, Wang AC, Ellingson BM, Rytlewski JA, Sanders CM, Kawaguchi ES, Du L, Li G, et al. Neoadjuvant anti-PD-1 immunotherapy promotes a survival benefit with intratumoral and systemic immune responses in recurrent glioblastoma. Nat Med. 2019; 25:477-86. https://doi. org/10.1038/s41591-018-0337-7. [PubMed]

26. Zeng J, See AP, Phallen J, Jackson CM, Belcaid Z, Ruzevick J, Durham N, Meyer C, Harris TJ, Albesiano E, Pradilla G, Ford E, Wong J, et al. Anti-PD-1 Blockade and Stereotactic Radiation Produce Long-Term Survival in Mice With Intracranial Gliomas. Int J Radiat Oncol Biol Phys. 2013; 86:343-49. https://doi.org/10.1016/j.ijrobp.2012.12.025. [PubMed]
27. Kim JE, Patel MA, Mangraviti A, Kim ES, Theodros D, Velarde E, Liu A, Sankey EW, Tam A, Xu H, Mathios D, Jackson CM, Harris-Bookman S, et al. Combination Therapy with Anti-PD-1, Anti-TIM-3, and Focal Radiation Results in Regression of Murine Gliomas. Clin Cancer Res. 2017; 23:124-36. https://doi.org/10.1158/1078-0432.CCR15-1535. [PubMed]

28. Wu A, Maxwell R, Xia Y, Cardarelli P, Oyasu M, Belcaid Z, Kim E, Hung A, Luksik AS, Garzon-Muvdi T, Jackson CM, Mathios D, Theodros D, et al. Combination antiCXCR4 and anti-PD-1 immunotherapy provides survival benefit in glioblastoma through immune cell modulation of tumor microenvironment. J Neurooncol. 2019; 143:241-49. https://doi.org/10.1007/s11060-019-03172-5. [PubMed]

29. Blumenthal DT, Yalon M, Vainer GW, Lossos A, Yust S, Tzach L, Cagnano E, Limon D, Bokstein F. Pembrolizumab: first experience with recurrent primary central nervous system (CNS) tumors. J Neurooncol. 2016; 129:453-60. https://doi.org/10.1007/s11060-016-2190-1. [PubMed]

30. Chamberlain MC, Kim BT. Nivolumab for patients with recurrent glioblastoma progressing on bevacizumab: a retrospective case series. J Neurooncol. 2017; 133:561-69. https://doi.org/10.1007/s11060-017-2466-0. [PubMed]

31. Grossman SA, Ye X, Lesser G, Sloan A, Carraway H, Desideri S, Piantadosi S, and NABTT CNS Consortium. Immunosuppression in patients with high-grade gliomas treated with radiation and temozolomide. Clin Cancer Res. 2011; 17:5473-80. https://doi.org/10.1158/1078-0432.CCR11-0774. [PubMed]

32. Thomas AA, Fisher JL, Hampton TH, Christensen BC, Tsongalis GJ, Rahme GJ, Whipple CA, Steel SE, Davis $\mathrm{MC}$, Gaur AB, Lewis LD, Ernstoff MS, Fadul CE. Immune modulation associated with vascular endothelial growth factor (VEGF) blockade in patients with glioblastoma. Cancer Immunol Immunother. 2017; 66:379-89. https:// doi.org/10.1007/s00262-016-1941-3. [PubMed]

33. Hughes MA, Parisi M, Grossman S, Kleinberg L. Primary brain tumors treated with steroids and radiotherapy: low CD4 counts and risk of infection. Int J Radiat Oncol Biol Phys. 2005; 62:1423-26. https://doi.org/10.1016/j. ijrobp.2004.12.085. [PubMed]

34. Omuro A, DeAngelis LM. Glioblastoma and other malignant gliomas: a clinical review. JAMA. 2013; 310:1842-50. https://doi.org/10.1001/jama.2013.280319. [PubMed]

35. Gustafson MP, Lin Y, New KC, Bulur PA, O'Neill BP, Gastineau DA, Dietz AB. Systemic immune suppression in glioblastoma: the interplay between CD14+HLA-DRlo/ neg monocytes, tumor factors, and dexamethasone. Neuro Oncol. 2010; 12:631-44. https://doi.org/10.1093/neuonc/ noq001. [PubMed]

36. Wong ET, Lok E, Gautam S, Swanson KD. Dexamethasone exerts profound immunologic interference on treatment efficacy for recurrent glioblastoma. Br J Cancer. 2015; 113:232-41. https://doi.org/10.1038/bjc.2015.238. [PubMed] 
37. Chongsathidkiet P, Jackson C, Koyama S, Loebel F, Cui X, Farber SH, Woroniecka K, Elsamadicy AA, Dechant CA, Kemeny HR, Sanchez-Perez L, Cheema TA, Souders NC, et al. Sequestration of T cells in bone marrow in the setting of glioblastoma and other intracranial tumors. Nat Med. 2018; 24:1459-68. https://doi.org/10.1038/s41591-018-0135-2. [PubMed]

38. Klemm F, Maas RR, Bowman RL, Kornete M, Soukup K, Nassiri S, Brouland JP, Iacobuzio-Donahue CA, Brennan C, Tabar V, Gutin PH, Daniel RT, Hegi ME, Joyce JA. Interrogation of the Microenvironmental Landscape in Brain Tumors Reveals Disease-Specific Alterations of Immune Cells. Cell. 2020; 181:1643-60.e17. https://doi. org/10.1016/j.cell.2020.05.007. [PubMed]

39. Reardon DA, Gokhale PC, Klein SR, Ligon KL, Rodig SJ, Ramkissoon SH, Jones KL, Conway AS, Liao X, Zhou J, Wen PY, Van Den Abbeele AD, Hodi FS, et al. Glioblastoma Eradication Following Immune Checkpoint Blockade in an Orthotopic, Immunocompetent Model. Cancer Immunol Res. 2016; 4:124-35. https://doi.org/10.1158/2326-6066. CIR-15-0151. [ [PubMed]

40. Dejaegher J, Verschuere $\mathrm{T}$, Vercalsteren E, Boon L, Cremer J, Sciot R, Van Gool SW, De Vleeschouwer S. Characterization of PD-1 upregulation on tumor-infiltrating lymphocytes in human and murine gliomas and preclinical therapeutic blockade. Int J Cancer. 2017; 141:1891-900. https://doi.org/10.1002/ijc.30877. [PubMed]

41. Mohme M, Schliffke S, Maire CL, Rünger A, Glau L, Mende KC, Matschke J, Gehbauer C, Akyüz N, Zapf S, Holz M, Schaper M, Martens T, et al. Immunophenotyping of Newly Diagnosed and Recurrent Glioblastoma Defines Distinct Immune Exhaustion Profiles in Peripheral and Tumor-infiltrating Lymphocytes. Clin Cancer Res. 2018; 24:4187-200. https://doi.org/10.1158/1078-0432.CCR-172617. [PubMed]

42. Kather JN, Suarez-Carmona M, Charoentong P, Weis CA, Hirsch D, Bankhead P, Horning M, Ferber D, Kel I, Herpel E, Schott S, Zörnig I, Utikal J, et al. Topography of cancerassociated immune cells in human solid tumors. Elife. 2018; 7:e36967. https://doi.org/10.7554/eLife.36967. [PubMed]

43. Park J, Kim CG, Shim JK, Kim JH, Lee H, Lee JE, Kim MH, Haam K, Jung I, Park SH, Chang JH, Shin EC, Kang SG. Effect of combined anti-PD-1 and temozolomide therapy in glioblastoma. Oncoimmunology. 2018; 8:e1525243. https:// doi.org/10.1080/2162402X.2018.1525243. [PubMed]

44. Candolfi M, Curtin JF, Nichols WS, Muhammad AG, King GD, Pluhar GE, McNiel EA, Ohlfest JR, Freese AB, Moore
PF, Lerner J, Lowenstein PR, Castro MG. Intracranial glioblastoma models in preclinical neuro-oncology: neuropathological characterization and tumor progression. J Neurooncol. 2007; 85:133-48. https://doi.org/10.1007/ s11060-007-9400-9. [PubMed]

45. McGahan BG, Neilsen BK, Kelly DL, McComb RD, Kazmi SA, White ML, Zhang Y, Aizenberg MR. Assessment of vascularity in glioblastoma and its implications on patient outcomes. J Neurooncol. 2017; 132:35-44. https://doi. org/10.1007/s11060-016-2350-3. [PubMed]

46. Mu L, Yang C, Gao Q, Long Y, Ge H, DeLeon G, Jin L, Chang YE, Sayour EJ, Ji J, Jiang J, Kubilis PS, Qi J, et al. CD4+ and Perivascular Foxp3+ T Cells in Glioma Correlate with Angiogenesis and Tumor Progression. Front Immunol. 2017; 8:1451. https://doi.org/10.3389/fimmu.2017.01451. [PubMed]

47. Smolders J, Remmerswaal EBM, Schuurman KG, Melief J, van Eden CG, van Lier RAW, Huitinga I, Hamann J. Characteristics of differentiated CD8(+) and CD4(+) T cells present in the human brain. Acta Neuropathol. 2013; 126:525-35. https://doi.org/10.1007/s00401-013-1155-0. [PubMed]

48. Hussain SF, Yang D, Suki D, Aldape K, Grimm E, Heimberger AB. The role of human glioma-infiltrating microglia/macrophages in mediating antitumor immune responses. Neuro Oncol. 2006; 8:261-79. https://doi. org/10.1215/15228517-2006-008. [PubMed]

49. Fu W, Wang W, Li H, Jiao Y, Huo R, Yan Z, Wang J, Wang S, Wang J, Chen D, Cao Y, Zhao J. Single-Cell Atlas Reveals Complexity of the Immunosuppressive Microenvironment of Initial and Recurrent Glioblastoma. Front Immunol. 2020; 11:835. https://doi.org/10.3389/ fimmu.2020.00835. [PubMed]

50. Garon EB, Rizvi NA, Hui R, Leighl N, Balmanoukian AS, Eder JP, Patnaik A, Aggarwal C, Gubens M, Horn L, Carcereny E, Ahn MJ, Felip E, et al, and KEYNOTE-001 Investigators. Pembrolizumab for the treatment of nonsmall-cell lung cancer. N Engl J Med. 2015; 372:2018-28. https://doi.org/10.1056/NEJMoa1501824. [PubMed]

51. Zhu J, Armstrong AJ, Friedlander TW, Kim W, Pal SK, George DJ, Zhang T. Biomarkers of immunotherapy in urothelial and renal cell carcinoma: PD-L1, tumor mutational burden, and beyond. J Immunother Cancer. 2018; 6:4. https://doi.org/10.1186/s40425-018-0314-1. [PubMed] 